The Journal of

Thoracic and Cardiovascular

Surgery

Vol 130, No. 4, October 2005

\title{
For everything there is a season
}

Tirone E. David, MD

From the Division of Cardiovascular Surgery of Toronto General Hospital and University of Toronto, Toronto, Ontario, Canada.

Read at the Eighty-fifth Annual Meeting of The American Association for Thoracic Surgery, San Francisco, Calif, April 10-13, 2005.

Received for publication April 22, 2005; accepted for publication May 9, 2005.

Address for reprints: Tirone E. David, MD, 200 Elizabeth St-4N457, Toronto, Ontario, Canada M5G 2C4 (E-mail: tirone. david@uhn.on.ca).

J Thorac Cardiovasc Surg 2005;130:961-5

$0022-5223 / \$ 30.00$

Copyright (c) 2005 by The American Association for Thoracic Surgery

doi:10.1016/j.jtcvs.2005.05.031
I would like to thank the nominating committee and the members of The American Association for Thoracic Surgery for honoring and entrusting me with the presidency of this prestigious academic organization. I have to share this honor with my colleagues from Toronto General Hospital for supporting me and sharing my views on patient care, teaching, and research for so many years.

I am indebted to the late Dr Bill Bigelow, a past president of The American Association for Thoracic Surgery and the person responsible for bringing me to Canada.

I am grateful to Bob Jones, Cindy VerColen, Bill Maloney, and their supporting staff for helping to make my tenure as president interesting, rewarding, and painless.

Finally, I must thank my wife, Jacqueline, who has put up with me for more than 30 years with understanding, grace, and compassion, which I am not sure I always deserved. Jackie has supported my professional growth unconditionally and never imposed any interfering demands. Jackie, I am grateful, admiring, and sometimes astonished. Jackie single-handedly raised three wonderful human beings: all three, fortunately, are much like her, our daughters, Adriane, Carolyn, and Kristen.

This address is about changes in cardiac surgery and my views on excellence in patient care. The title was borrowed from the book of Ecclesiastes, which contains the thoughts of a philosopher who reflected on how short and contradictory life was. I read the Bible as a child, but the meaning of the words "for everything there is a season" made no sense until I was 14 years old. Two painful events occurred within a few months that year: my parents sent me away from home to attend high school, where initially I felt lost and abandoned, and my paternal grandfather died. It was then that I learned that "for everything there is a season, and a time for every purpose under heaven"- that life is a dynamic process, and its only certainty is change. It changes not only when we leave our homes or lose a loved one, but in all aspects.

We who practice medicine know that changes are happening all the time as new drugs, concepts, and techniques emerge. Much more than that, the way we practice medicine is changing. The truth is that medicine is no profession for the status quo.

Cardiac surgery is no exception. In fact, our work is at the epicenter of change in all aspects. Clinical volumes are declining, cardiologists now treat many patients with devices that can be deployed percutaneously, and so on. Furthermore, accountability is at an all-time high. These are the realities we have to live with and adjust to as best we can.

One of the most dramatic changes in cardiothoracic surgery occurred in the late 1960s, when coronary artery bypass grafting (CABG) was introduced into the treatment of coronary artery disease. Cardiothoracic surgeons who operated on lungs, esophagus, and heart valves had to acquire a new set of skills to perform myocardial revascularization. They did it and did it very well. Within a few years, a new breed of thoracic surgeons emerged - the CABG surgeon-and the number of 


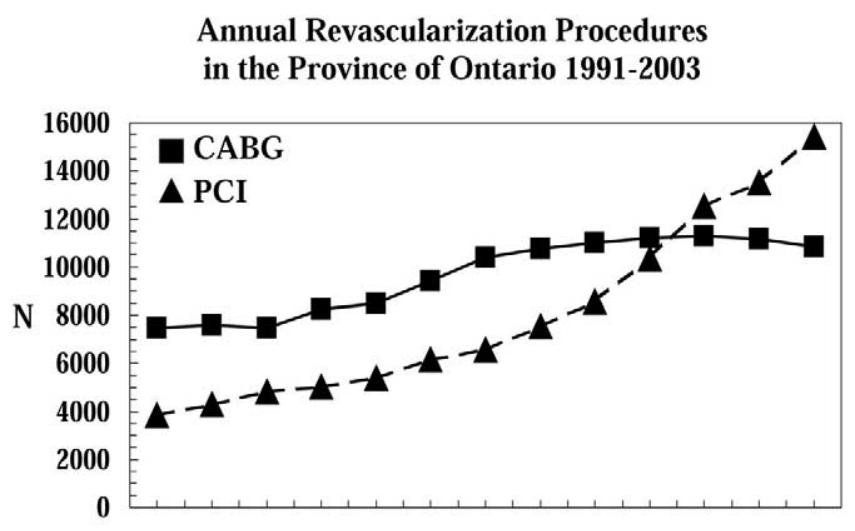

$\begin{array}{lllllllllllll}91 & 92 & 93 & 94 & 95 & 96 & 97 & 98 & 99 & 00 & 01 & 02 & 03\end{array}$

Figure 1. Trends in myocardial revascularization in Ontario, Canada (1991-2003). Source: Cardiac Care Network of Ontario. CABG, Coronary artery bypass grafting; $\mathrm{PCl}$, percutaneous coronary intervention.

operations increased by tens of thousands each year. They made coronary artery bypass surgery one of the most commonly performed operations in North America.

Percutaneous balloon angioplasty, an alternative method of myocardial revascularization, started some 10 years after $\mathrm{CABG}$, and the number of procedures also increased by tens of thousands each year without affecting the number of coronary artery bypass operations until recently. At present, in the Province of Ontario, Canada, almost twice as many patients undergo angioplasty as $\mathrm{CABG}$ for the management of coronary artery disease (Figure 1). These are changes, my friends. Real changes!

Cardiologists have made remarkable strides in perfecting the technical aspects of angioplasty, decreasing the inflammatory reaction associated with the deployment of stents, and, consequently, reducing the number of patients who need CABG. More important, lifestyle changes and improved pharmacologic management of atherosclerosis are reducing the prevalence of coronary artery disease. These developments are discouraging young surgeons from choosing cardiac surgery as their specialty. This is most unfortunate, because $\mathrm{CABG}$ will continue to have an important role in the management of this disease for years to come. Moreover, cardiac surgery is much more than CABG and needs young inquiring minds do the work that we have just begun. If only I could be a 30-year-old again!

Percutaneous endovascular interventions are not only changing the field of coronary artery disease. This technology has caused profound changes in the management of congenital heart disease and is now penetrating heart valve disease. We have to define the role of the cardiac surgeon in percutaneous endovascular interventions. I believe that we have to acquire the skills in this type of therapy because-if nothing else-they will likely play a major role in the management of thoracic aortic pathology and will be routinely used both in isolation and in combination with surgical procedures to treat patients with aneurysms. "For everything there is a season," and as the thoracic surgeons of the late 1960s learned CABG, we now have to learn percutaneous approaches to treat cardiovascular diseases.

During the past 20 years, there has been a disproportionate increase in the number of cardiac centers in relation to the number of angioplasties and CABGs in the United States. Close to 1000 hospitals in this country now offer these therapies. This growth has reduced the number of procedures per center and has made it more difficult to develop expertise in surgical or percutaneous cardiovascular interventions. The changes in the management of cardiovascular diseases, in addition to the demands for safety, effectiveness, and efficiency by public and health care regulators, will make it difficult for small units and low-volume cardiac surgeons and interventionists to deliver the expected quality of care. Public disclosure of clinical outcomes may further complicate things. Centralization of specialized cardiovascular services may become necessary, and lowvolume cardiac units may have to close. "For everything there is season...."

Another concern that demands attention is that operative procedures to treat cardiothoracic diseases are becoming more complicated and require a higher level of expertise to deliver excellence. These changes will force us to choose to practice one of the three subspecialties in cardiothoracic surgery: general thoracic surgery, surgery for acquired cardiac disease, or surgery for congenital heart disease.

The American Board of Thoracic Surgery has recognized the need for further subspecialization in thoracic surgery and is changing the requirements for training and certification. Thoracic surgery residents will have to choose between cardiothoracic or general thoracic surgery, and the training programs will have to provide greater exposure and experience in these areas. Inevitably, there will be fewer residents and training programs.

One thing we surgeons should never forget is that change is inevitable and is even desirable. Change in our line of work means progress, and for us progress should be improving the outcomes of diseases. Cardiologists and surgeons should work collaboratively to determine the best therapy. This sounds idealistic, but isn't our Hippocratic oath?

In his presidential address to this Association in 1998, Fred Loop ${ }^{1}$ said that "we have by now evolved from a mechanical art to more than an intermediate science, and with each advance, the enterprise has been more satisfying for patients and doctors. And the drama is still unfolding." The drama is indeed unfolding. 
Surgeons who reach a comfort zone and resist change may be enlightened by reading Dr Spencer Johnston's book, Who Moved My Cheese? It is a simple and amusing parable of four characters who live in a maze and look for cheese for nourishment and happiness. Two are mice named Sniff and Scurry, and two are "littlepeople," who are the size of mice but look and act a lot like humans. Their names are Hem and Haw. Cheese is a metaphor for whatever you want in life. Sniff, Scurry, Hem, and Haw found a cheese station in the maze and were happy. One day the cheese disappeared, and the mice, simple creatures, looked for cheese elsewhere and did well. Hem and Haw, more intelligent creatures, were perplexed and frustrated and analyzed the situation over and over. The days passed, and they grew hungry and unhappy. After a while, Haw realized that the cheese would not come back and ventured into dangerous parts of the maze in search of new cheese. He suffered, but eventually he found a bigger and better cheese station in the maze. To help his friend Hem who stayed behind, he wrote several sentences on the walls of the maze. Here are some of these writings on the wall:

- Change happens-They keep moving the cheese

- Anticipate changes-Get ready for the cheese to move

- Monitor changes-Smell the cheese often so you know when it is getting old

- Adapt to change quickly-The quicker you let go of old cheese, the sooner you can enjoy new cheese

- Change-Move with the cheese

- Enjoy change-Savor the adventure and enjoy the taste of new cheese

- Be ready to change quickly and enjoy it again and again-They keep moving the cheese

This is not a bad parable for us to remember and to practice.

Now that you have endured what I have said about changes, I would like to shift to an area that I think is critical and important-in many ways, the intangible aspects of patient care and excellence in clinical surgery.

Last year, Joel Cooper and I were discussing the role of the surgeon in clinical outcomes. He said that the clinical outcomes in general thoracic surgery were more dependent on judgment than on technical skills, whereas in cardiac surgery the reverse was true. Joel went on to tell me that the best cardiac surgeons he knew were uniformly gifted technicians but that the same was not true for the best general thoracic surgeons.

Frank Spencer, another past president of The American Association for Thoracic Surgery, once wrote that during the execution of an operation, $75 \%$ of the important events were related to making the right decisions and only $25 \%$ to manual skills. ${ }^{2}$

At recent rounds of the University of Toronto Department of Surgery, Ralph Manktelow, a professor of plastic surgery, compared the work of surgeons with the work of furniture craftsmen. He made reference to David Pye, who was a British architect and professor of furniture design at the Royal College of Art in London. Although Mr Pye died in 1993, his writings and teachings continue to influence the woodworking world today. In his book, The Nature and Art of Workmanship, published in 1968, he discusses the concept of workmanship of risk, in which the quality of work is dependent on judgment, dexterity, and care. He uses the term workmanship of risk because at any moment, whether because of lack of attention, inexperience, or accident, the workman might ruin the job. The opposite of workmanship of risk is workmanship of certainty, in which the quality of the result is determined before the thing is made, such as in automated production. I liked the comparison of wood carving to surgery because for years I have been telling our trainees that a surgeon's clinical outcomes depend on knowledge, judgment, dexterity, caring, and attention to detail. I am personally obsessed with attention to detail, but unlike Drs Cooper and Spencer, I believe that it is difficult, if not impossible, to quantify the relative importance of each of these elements in the outcome of surgery.

The explosion in the amount of medical knowledge in recent decades has forced us to become progressively more specialized to deliver excellence in patient care. At the cardiac unit where I work, we divided the clinical and academic responsibilities into areas such as off-pump CABG, heart valve surgery, surgery for dysrhythmias, thoracic aortic surgery, surgery for end-stage heart failure, and surgery for congenital heart disease in adults. This higher level of subspecialization in cardiac surgery has resulted in exemplary clinical outcomes and academic productivity. Moreover, the amount of knowledge that is disseminated through dialogues among players is far greater than what anyone could acquire in isolation. This is yet another compelling reason for centralization of specialized cardiac care.

Judgment evolves from knowledge, experience, and cognitive skills. Judgment in cardiothoracic surgery plays a vital role in all phases of surgical care: before, during, and after an operation. I believe that judgment during the execution of an operation is as crucial in cardiac as it is in general thoracic surgery or in any surgical specialty. Common sense is probably all that it takes for good surgical judgment, but because, according to Voltaire (FrancoisMarie Arouet Voltaire, 1694-1778), "common sense is uncommon," it takes much more than knowledge and experience to foster all aspects of surgical judgment. That is where cognitive skills become important. As for common sense, there is a saying in the Canadian army that could apply to surgery or any other field of expertise: "common sense is so rare that it is often mistaken for genius." Cynical, perhaps, but who could argue otherwise? 


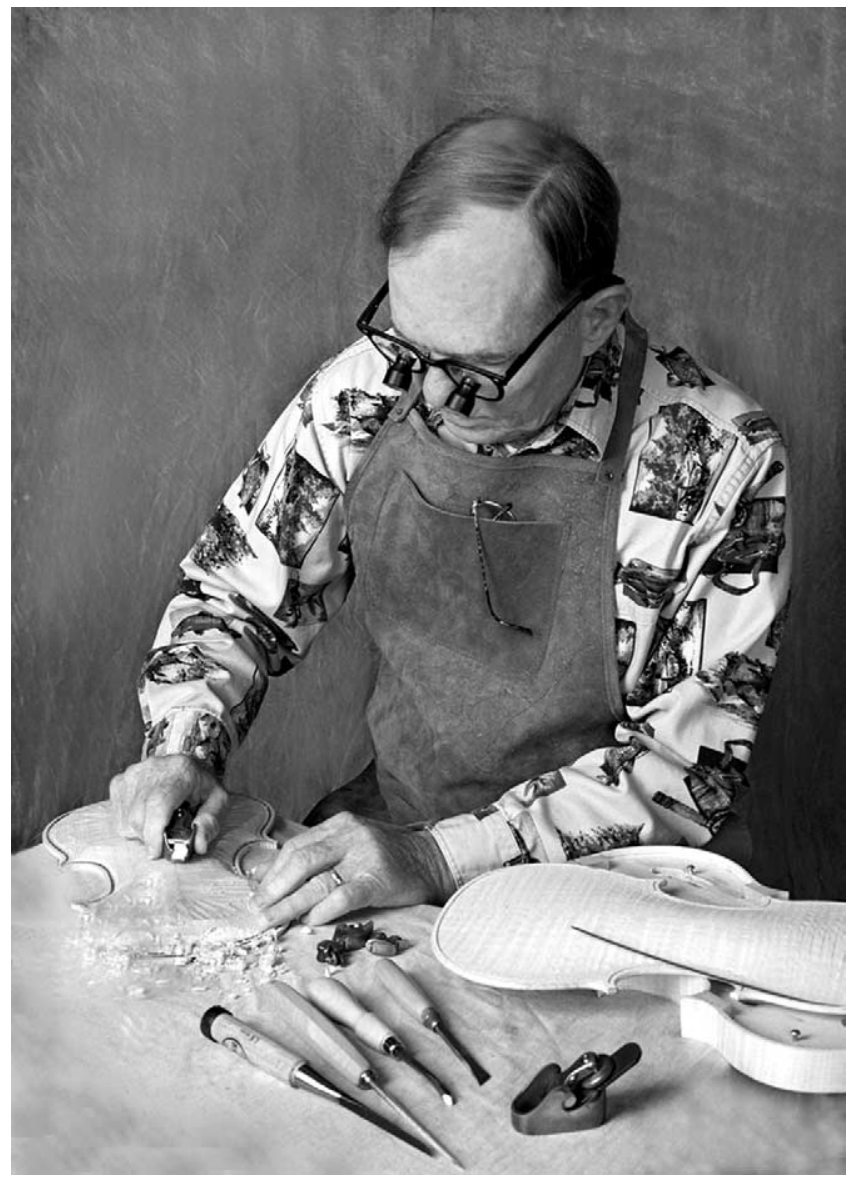

Figure 2. Noel Mills building his first violin (courtesy of Noel L. Mills, MD).

Surgery is a manual therapeutic tool, and, as such, dexterity is indispensable. The cognitive skills required to improve dexterity are different from those needed to acquire knowledge and judgment. Although it has been euphemistically said that a monkey can learn to operate, the basic elements needed to teach or improve dexterity remain elusive. There is evidence that repetition leads to perfection, and that is probably one of the reasons that high-volume surgeons have lower operative mortality and morbidity than low-volume surgeons. ${ }^{3}$ However, there must be an innate component of dexterity that explains the variability of technical skills and outcomes among high-volume surgeons.

Caring is crucial in the delivery of patient care. Caring involves a genuine interest in the patient's well-being as well as a conscious effort to cause no harm. Honesty, openness, and compassion enrich the quality of patient care. Ignorance, indifference, and carelessness do the opposite. Attempting to operate without adequate knowledge is a display of poor work ethics and lack of caring. I believe that

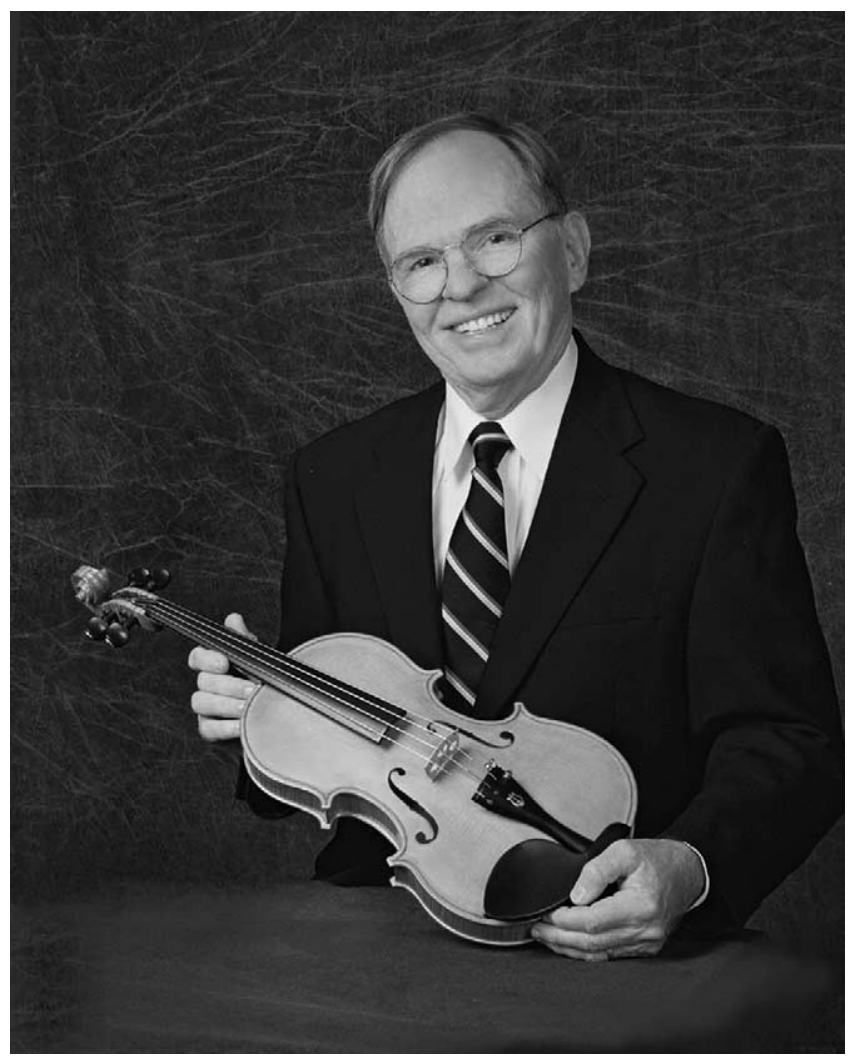

Figure 3. Noel Mills and one of his $\mathbf{1 0}$ violins (courtesy of Noel $\mathbf{L}$. Mills, MD).

caring is the most important component of work ethics in the practice of medicine.

Attention to detail is another important element in the making of excellence in patient care. Attention is a limited mental resource. It takes an incredible amount of self-discipline to remain focused throughout an operation. Another facet of this complex element is the ability to multitask-that is, simultaneously planning, forecasting, and executing the precise movements required to make the operation swift and flawless.

Lack of attention or the inability to multitask during an operation is the main reason that knowledgeable surgeons make technical errors. You can see why I liked the comparison of surgery to woodcarving. Mr Pye's term workmanship of risk certainly applies.

Noel Mills is a professor of surgery at Tulane University. As a diversion from a demanding work schedule as a surgical resident in New York City, he read an article titled "The Physics of Violins" written by Carleen Hutchins in Scientific American in 1962. Ms Hutchins had studied with Fernando Sacconi, an Italian violin maker and a leading authority on the work of Antonio Stradivari. Her research changed the way violins were made. After retiring from cardiac surgery, Noel 
visited Ms Hutchins and learned as much as he could about wood carving and violin making. In 1995, with knowledge, judgment, dexterity, caring, and attention to detail, he built his first violin (Figure 2). I can imagine what Noel experienced when a musician with the New Orleans Symphony played his violin in a performance (Figure 3). He has built 10 violins and is now working on his first cello.

Surgeons who rise above the expected level of competence are highly motivated and have the uncommon ability to concentrate during the performance of surgical procedures. These individuals excel in knowledge, judgment, and dexterity because every patient they care for is a source of new information: information that is stored, processed, and readily recalled when necessary. They have the mental ability to retain data acquired from their visual and tactile senses, as well as from the response to their manual actions during an operation. As their experience increases, they are able to conceptualize in 3 dimensions what to do when faced with problems they have never seen before. They are very resourceful, which is historically how most innovative operative procedures have been developed. Finally, they monitor their own performance obsessively and worry constructively. They worry because they care.
I believe that there is need to better understand the interactions of knowledge, judgment, dexterity, caring, and attention to detail to train future surgeons because they will be the ones who will develop new therapeutic approaches to treat patients with cardiothoracic diseases. They will be making the changes in our specialty. Change is good. Change is necessary. Change is progress.

Reinhold Niebuhr (1892-1971), an American theologian, left a legacy in writings that enrich our spirits. My favorite is "God grant me the serenity to accept things I cannot change, the courage to change things I can, and the wisdom to know the difference."

Thank you for your attention and trust.

\section{References}

1. Loop FD. Thoracic and cardiovascular surgery. Presidential address. J Thorac Cardiovasc Surg. 1998;116:683-8.

2. Spencer FC. Teaching and measuring surgical techniques-the technical evaluation of competence. Bull Am Coll Surg. 1978;63:9-12.

3. Birkmeyer JD, Stukel TA, Sievers AE, Goodney PP, Wennberg DE, Lucas FL. Surgeon volume and operative mortality in the United States. N Engl J Med. 2003;349:2117-27. 